\title{
Efficiency of vaginal electrical impedance to determine the stage of the reproductive cycle in bitches ${ }^{1)}$
}

\author{
HANDE GÜRLER, ECE KOLDAŞ*, FIRDEVS BINLI ÖNYAY, AYTAÇ AKÇAY**
}

\author{
Department of Obstetrics and Gynecology, Faculty of Veterinary Medicine, \\ Ondokuz Mayıs University, Kurupelit, Samsun, 55139, Turkey \\ *Department of Obstetrics and Gynecology, Faculty of Veterinary Medicine, \\ Mustafa Kemal University, Antakya, Hatay, 31000, Turkey \\ **Department of Biometry, Faculty of Veterinary Medicine, Erciyes University, Talas, Kayseri, 38039, Turkey
}

Gürler H., Koldaş E., Binli Önyay F., Akçay A.

\section{Efficiency of vaginal electrical impedance to determine the stage of the reproductive cycle in bitches}

Summary

A study was carried out to compare the efficiency of vaginal electrical impedance with serum progesterone profile, cytological examination and clinical findings. Vaginal electrical impedance values varied at the different stages of the estrous cycle, with the highest value during the transition into estrous and the lowest in diestrus $(P<0.05)$. There was a negative statistical correlation between serum progesterone values and the impedance values $(36 \%)(P<0.001)$. Vaginal electrical impedance was a faster and cheaper method than progesterone assessment. It was more reliable than vaginal cytology and clinical evaluation. In conclusion, a combination of vaginal electrical impedance measurements and progesterone evaluation was a more useful method for determination of the optimal breeding time in bitches.

Keywords: bitch, ovulation detection, vaginal cytology, vaginal impedance

The period between two-estrous cycles is relatively long (between 4.5 and 13 months; a mean of 7 months) and varies among different breeds of bitches. Ovulation time for the recurrent estrous period of the same bitch can also vary. These factors combine to cause uncertainty in the determination of optimal breeding time, for which the clinical signs of estrous are generally used. This method is not satisfactory given that the ovulation time is not fixed in the 5 to 30 day period of estrous. Therefore, various methods for predicting ovulation, including serum or plasma hormone concentration, vaginal cytology, vaginal electrical impedance (VEI), vaginal endoscopy and ultrasonography (USG) evaluation of the ovary, have been employed $(3,7,9,10)$.

While various methods are developed and routinely used for the determination of optimum time these have some disadvantages, such as the need for experienced personnel or a late result when used on its own. Therefore, a combined use of these methods is

\footnotetext{
1) This study was supported by University Ondokuz Mayıs University (Project Id: PYO.VET. 1901.12.007). The authors also thank Gregory T. Sullivan of the School of Geography, Planning and Environmental Management at the University of Queensland in Brisbane, Australia for editing the English in an earlier version of this manuscript.
}

recommended. The multiple method, vaginal cytology + P4 testing + LH hormone concentration and USG if necessary, is regarded the current gold standard for accuracy in predicting the time of ovulation $(1,5,8$, 11). When quick results in the field are demanded, a one-alone method such as VEI can be used.

The aim of this study was to compare the efficiency of VEI with P4 profiling, cytological examination and clinical findings to determine the stage of the reproductive cycle of bitches.

\section{Material and methods}

Animals. The fifteen bitches used in the study were between 1.5 and 5 years of age, and 12 and $33 \mathrm{~kg}$ in weight. They were deemed healthy in clinical and gynecological evaluations and there was no recorded or recollected history of genital organ disease in anamnesis. All of the bitches were examined daily for a minimum of three times with clinical, cytological and hormone analyses, as well as VEI. All samples such as cytology, blood serum and electrical impedance were obtained at the same time from the same animal. Ethical approval for the study was obtained from the Animal Ethics Committee, Ondokuz Mayis University, Samsun, Turkey (Approval No: 201001). 
The 15 bitches were collectively examined a total of 76 times according to clinically, cytologically and serum P4 analyses. Furthermore, the sexual cycle (proestrus, estrous or diestrus) of each animal was determined using these three methods combined.

Clinical and cytological examinations. Vaginal edema and serosanguineous discharge were evaluated clinically and vaginal smear samples were collected from all 15 bitches. Two slides were prepared from each sample and stained with the Papanicolaou method (1). Determination of phases of the estrous cycle was completed according the method of Aydin et al. (2), using a light microscope $\left(\mathrm{NIKON}^{\circledR}\right.$ eclipse $\left.80 \mathrm{i}\right)$ at $\times 10$ and $\times 40$ magnification. The smears were investigated for cell morphology, cell group percentage and acidophilic index (AcI) (2). In this study the authors created 3 different groups based on the vaginal cytological state; namely group I (ready to be inseminated), group II (not ready to be inseminated) and Group III (doubtful). In group I, samples had different types of cells and the proportion of superficial cells (anuclear cornified squamous cells) was above $80 \%$ (4). In Group III, the superficial cells were cornified and the proportion of pyknotic nuclei was approximately $80 \%$.

Measuring the electrical impedance. A manual dogspecific ovulation detector (Draminski ${ }^{\circledR}$ ) was utilized to measure electrical impedance of the vaginal mucus. The probe was washed under running water and disinfected with chlorhexidine before each VEI was recorded. This process was repeated at least 3 times for each measurement and the mean value was used in analyses. A total of 76 electrical impedance data were collected through the estrous cycles of the 15 bitches.

Serum P4 analyses. Blood samples were collected from each animal at two day intervals from the v. cephalica antebrachii into vacutainer serum tubes and centrifuged at $4{ }^{\circ} \mathrm{C}$ for $10 \mathrm{~min}$ at $3000 \mathrm{rpm}$. The serum obtained was stored at $-20^{\circ} \mathrm{C}$ until $\mathrm{P} 4$ hormone profiling was conducted, modified from Gier et. al. (5). The analyses were performed with the electrochemiluminescence immunoassay (ECLIA) method by using a Roche E170 modular device (5).

Statistical analysis. One-way analysis of variance (ANOVA) and the Tukey multiple pairwise tests were used for comparisons between clinical examination findings and VEI. The relationship between P4 values and VEI was investigated by the comparison of Pearson correlation coefficients. The statistical analyses were done with the SPSS 14.01 (License Number: 986964) software package.

\section{Results and discussion}

The VEI of bitches showed differences related to the period of their cycle. There was a positive correlation in estrous and a negative correlation in diestrus $(\mathrm{P}<0.05)$ (Tab. 1).

There was a highly significant negative correlation $(36 \%)$ between blood P4 values and VEI $(\mathrm{P}<0.001)$ (Tab. 2). One unit of increase in blood progesterone level caused a 5 unit decrease in VEI (Fig. 1).

Conversely, there was a highly statistically significant relationship between edema and VEI $(\mathrm{P}<0.001)$ (Tab. 3). The relationship between VEI value and vagi-
Tab. 1. Vaginal electrical impedance changes during the estrous cycle in bitches

\begin{tabular}{|c|c|c|c|c|}
\hline \multirow{2}{*}{$\begin{array}{l}\text { Clinical } \\
\text { Status }\end{array}$} & \multicolumn{4}{|c|}{ Vaginal Electrical Impedance } \\
\hline & $n$ & Mean \pm SEM & Min & Max \\
\hline Proestrus & 17 & $408.1 \pm 91.52^{\mathrm{ab}}$ & 80 & 1270 \\
\hline Estrous & 16 & $617.5 \pm 78.37^{a}$ & 220 & 1410 \\
\hline Diestrus & 43 & $333.9 \pm 48.17^{b}$ & 100 & 1290 \\
\hline \multicolumn{5}{|c|}{ Statistical significance (ANOVA) } \\
\hline
\end{tabular}

Explanation: $\mathrm{a}, \mathrm{b}-$ means with different letters are statistically significant $(\mathrm{P}<0.05)$

Tab. 2. Relationship between VEI and blood P4 values

\begin{tabular}{|c|c|}
\hline & Vaginal Electrical Impedance \\
\hline P4 & -0.364 \\
& $\mathbf{P}<\mathbf{0 . 0 0 1}$ \\
\hline
\end{tabular}

Tab. 3. The relationship between clinical evaluation results and VEI for bitches

\begin{tabular}{|c|c|c|c|c|c|}
\hline \multirow{2}{*}{\multicolumn{2}{|c|}{ Clinical signs }} & \multirow{3}{*}{$\begin{array}{c}n \\
31\end{array}$} & \multicolumn{3}{|c|}{ Vaginal Electrical Impedance } \\
\hline & & & \multirow{2}{*}{$\begin{array}{l}\text { Mean } \pm \text { SEM } \\
228.4 \pm 29.2^{\mathrm{a}}\end{array}$} & \multirow{2}{*}{$\begin{array}{l}\text { Min } \\
100\end{array}$} & \multirow{2}{*}{$\begin{array}{r}\text { Max } \\
780\end{array}$} \\
\hline \multirow{3}{*}{ Edema } & Yes & & & & \\
\hline & No & 30 & $588.8 \pm 71.6^{b}$ & 100 & 1410 \\
\hline & \pm & 15 & $428.7 \pm 88.3^{a b}$ & 80 & 1290 \\
\hline \multicolumn{3}{|c|}{ Statistical significance (ANOVA) } & \multicolumn{3}{|c|}{$F: 10,52 \quad P<0.001$} \\
\hline \multirow{3}{*}{$\begin{array}{l}\text { Blood } \\
\text { Discharge }\end{array}$} & No & 52 & $365.3 \pm 44.2$ & 80 & 1410 \\
\hline & Yes & 16 & $525.5 \pm 94.2$ & 100 & 1270 \\
\hline & \pm & 8 & $471.3 \pm 147.5$ & 120 & 1290 \\
\hline \multicolumn{3}{|c|}{ Statistical significance (ANOVA) } & \multicolumn{3}{|c|}{$F: 1.485 \quad P>0.05$} \\
\hline
\end{tabular}

Explanation: as in Tab. 1

Tab. 4. Relationship between VEI and vaginal cytology groups for bitches

\begin{tabular}{|l|c|c|r|r|}
\hline \multirow{2}{*}{ Vaginal cytology } & \multirow{2}{*}{$\mathrm{n}$} & \multicolumn{3}{c|}{ Vaginal Electrical Impedance } \\
& & Mean \pm SEM & Min & Max \\
\hline Group I & 23 & $249.0 \pm 42.1^{\mathrm{a}}$ & 80 & 837 \\
Group II (>80\% CSF) & 38 & $487.0 \pm 58.4^{\mathrm{b}}$ & 100 & 1410 \\
Group III & 15 & $462.7 \pm 105.1^{\mathrm{b}}$ & 120 & 1290 \\
\hline Statistical significance (ANOVA) & \multicolumn{3}{|c|}{ F: $3.93 \mathrm{P}<0.05$} \\
\hline
\end{tabular}

Explanation: as in Tab. 1

nal cytology findings was lowest for Group 1 (Tab. 4) and highest for Group II (Tab. 4; Fig. 2).

The time of ovulation should be accurately determined for the artificial insemination of bitches because frozen spermatozoa rapidly lose their vitality $(7,10)$. Vaginal cytology cannot accurately predict the time of ovulation and is therefore not effective in artificial insemination $(6,10)$. This study showed that the impedance values and regular clinical findings are correlated. VEI values varied at the different stages of the estrous cycle, with the highest value during the transition into estrous and the lowest in diestrus $(\mathrm{P}<0.05)$, while there were no significant differences between proestrus and estrous. It was therefore determined that VEI could not 


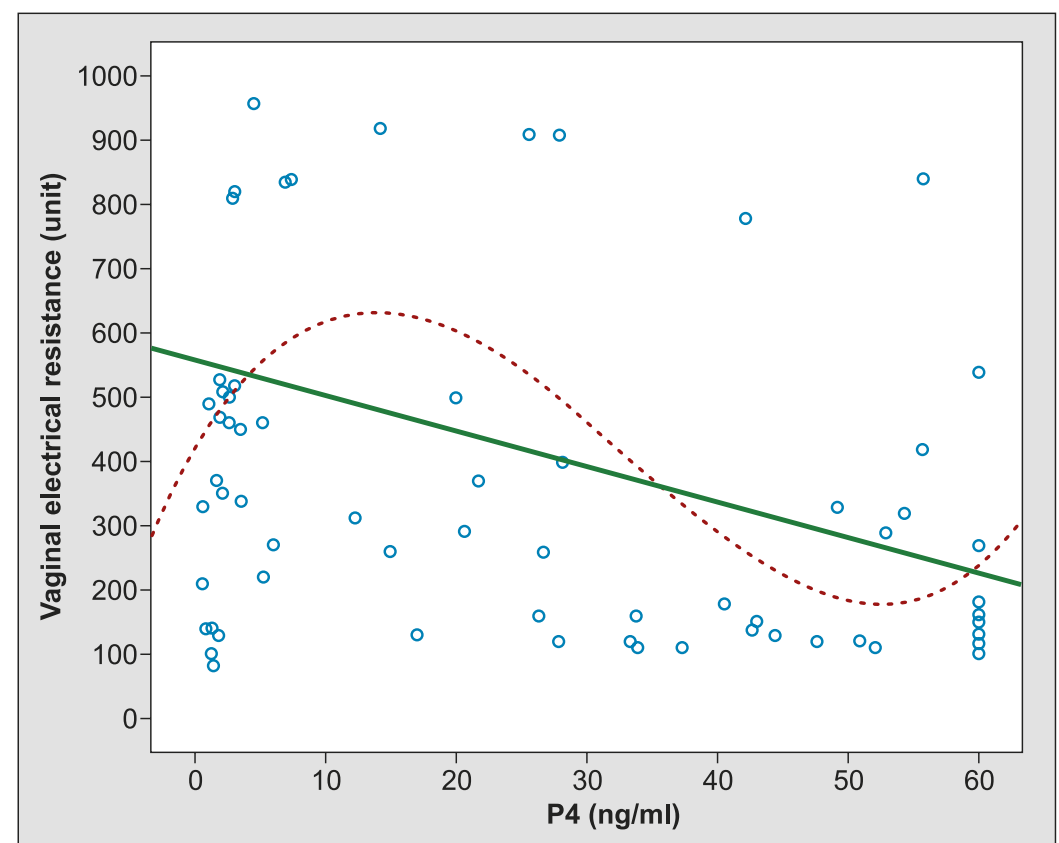

Fig. 1. Relationship of VEI values and P4 values in the blood of bitches

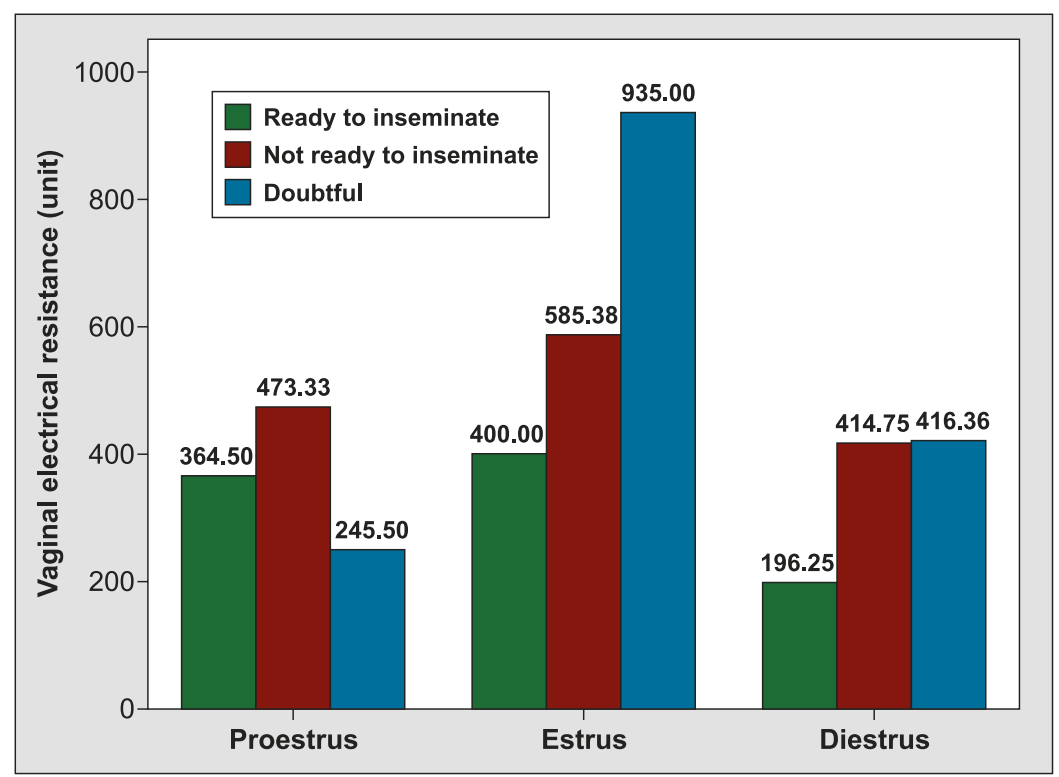

Fig. 2. Relationship of VEI values during estrous to clinical signs and vaginal cytology findings indicating breeding status in bitches

be used alone for the determination of ovulation time in bitches. As mentioned by Bergeron et al. (3) the use of vaginal impedometry in conjunction with the other methods such hormone assays will give more reliable information than on its own.

The relationship between VEI and P4 was statistically significant $(\mathrm{P}<0.05)$. The most important signs for the determination of the phase of the cycle are discharge and edema and they were correlated with VEI $(\mathrm{P}<0.05)$. The level of luteinizing hormone peaks when the edema starts to resolve, which means the oocyte will be ready to enter the genital canal 4-5 days later (2). Furthermore, results indicated that the best time for mating is 1-2 days after the highest VEI value is recorded, which is in agreement with the specifications of the manufacturer.
Although it is possible to obtain numerical values with AcI in vaginal cytology, it needs to be carried out regularly by the same expert. Therefore, this method is regarded as relatively impractical. Our results matched those of a different study (6) which showed that cytology alone is insufficient for the determination of the correct time for insemination.

In conclusion, VEI with the combined use of hormone measurements can predict the ideal time for insemination in bitches and may also be useful in situations where it is not possible to regularly check hormone levels. Furthermore, in this study VEI was a more reliable method than vaginal cytology. On the other hand we believe that what will give the most reliable results is the use of multiple methods. Additionally, it is important that the VEI device probe might be a potential risk of diseases spreading because it is impossible to sterilize it. Therefore, we suggest that the manufacturer should be pressed to modify the probe.

\section{References}

1. Aissi A., Alloui C., Slimani C., Touri S.: Preliminary study of the early ultrasonic diagnosis of pregnancy and fetal development in the dog. J. Anim. Vet. Adv. 2008, 7, 607-611.

2. Aydın I., Sur E., Ozaydın T., Dinç D. A.: Determination of the stages of the sexual cycle of the bitch by direct examination. J. Anim. Vet. Adv. 2011, 10, 1962-1967.

3. Bergeron L. H., Nykamp S. G., Brisson B. A., Madan P., Sears W., Gartley C. J.: Vaginal impedometry for detection of optimal breeding time in bitches. JAVMA 2014, 245, 1360-1366.

4. England G., Concannon P. W.: Determination of the optimal breeding time in the bitch: Basic considerations, [in:] Concannon P. W., England G., Verstegen J. (ed.): Advances in Small Animal Reproduction. 1. International Veterinary Information Service, New York 2002, p. 11.

5. Gier J., Kooistra H. S., Djajadiningrat-Laanen S. C., Dielman A. J., Okkens A. C.: Differential regulation of the secretion of luteinizing hormone and follicle-stimulating hormone around the time of ovulation in the bitch. Theriogenology 2006, 66, 1419-1422.

6. Hiemstra M., Schaefers-Okkens A. C., Kooistra H. S.: The reliability of vaginal cytology in determining the optimal mating time in the bitch. Tijdschr. Diergeneesk. 2001, 21, 685-689.

7. Kim B. S., Son C. H.: Time of initial detection of fetal and extra-fetal structures by ultrasonographic examination in Miniature Schnauzer bitches. J. Vet. Sci. 2001, 8, 289-293.

8. Kutzler M. A., Mohammed H. O., Lamb S. V., Meyera-Wallen V. N.: Accuracy of canine parturition date prediction from the initial rise in preovulatory progesterone concentration. Theriogenology 2003, 60, 1187-1196.

9. Lenard Z. M., Hopper B. J., Lester N. V., Richardson J. L., Robertson I. D.: Accuracy of prediction of canine litter size and gestational age with ultrasound. Aust. Vet. J. 2007, 85, 222-225.

10. Levy X., Fontbonne A.: Determining the optimal time of mating in bitches: particularities. Rev. Bras. Reprod. Anim. 2007, 31, 128-134.

11. Yener T., Turkkani-Tunc A., Aslan H., Cantug Caliskan A.: Determination of oetrous cycle of the rats by direct examination: how reliable? Anat. Histol. Embryol. 2007, 36, 75-77.

Corresponding author: Hande Gürler, DVM, PhD., Department of Obstetrics and Gynecology, Faculty of Veterinary Medicine, Ondokuz Mayıs University, Kurupelit, Samsun, 55139, Turkey; e-mail: handeulusoy@ gmail.com 